\title{
Dissolution testing of bilayer tablets: Method development, validation and application in post-marketing quality evaluation
}

\author{
Amjad Khan ${ }^{1, *}$ and Zafar Iqbal²
}

${ }^{1}$ Department of Pharmacy, Abasyn University, Peshawar, Pakistan

${ }^{2}$ Department of Pharmacy, University of Peshawar, Peshawar, Pakistan

e-mail: amjadph@gmail.com

\section{ABSTRACT}

Bilayer tablets are gaining importance as they provide a multilayer system for administration of incompatible or synergistic drugs and reduce the dosing unit burden. Furthermore, two different APIs or portions of an API with different release characteristics can be formulated as single unit, having different layers. Most of the research is directed towards physical stability (prevention of delamination), and simultaneous dissolution testing of different APIs in bilayer tablets has been neglected. In the present study, a method was developed for simultaneous determination of dissolution rates of clopidogrel and aspirin from bilayer tablets. Dissolution media was selected on the basis of sink conditions for both the drugs. Various experimental conditions (type of apparatus, agitation rate, and volume of dissolution media) were optimized, and the developed method was validated according to USP and ICH guidelines. Analysis of dissolution samples was carried out by HPLC using an ODS C-18 column $(250 \times 4.6 \mathrm{~mm}, 5 \mu \mathrm{m})$ as the stationary phase. The mobile phase consisted of a combination of acetonitrile, methanol, and phosphate buffer (50:7:43, v/v/v) pumped at flow rate of 2 $\mathrm{mL} / \mathrm{min}$ at ambient temperature while the detector wavelength was set at $240 \mathrm{~nm}$. An independent model approach was applied for comparison of dissolution profiles. The best in vitro dissolution profiles were obtained using $900 \mathrm{~mL}$ of hydrochloric acid $(\mathrm{HCl})$ buffer $(\mathrm{pH} 3)$ as dissolution media held at $37 \pm 2^{\circ} \mathrm{C}$ and stirred at $75 \mathrm{rpm}$ using apparatusII. Complete dissolution was achieved within $45 \mathrm{~min}$. for both the drugs. Validation parameters revealed accuracy, precision, and robustness of the method without any interference with sample analysis. The developed method will be helpful in dissolution testing of bilayer tablets containing clopidogrel and aspirin at the level of product development and during routine quality control analysis and post-marketing surveillance studies.

KEYWORDS: Bilayer tablets, clopidogrel, aspirin, method validation, $\mathrm{ICH}$ guideline, dissolution

\section{INTRODUCTION}

D issolution testing is used to measure the rate of drug release from a solid dosage form (1). Dissolution can be the rate-limiting step for drug absorption and is used to assess performance of the dosage form at different stages of product life cycle, ranging from product development to post-marketing surveillance (2). It is a basic tool for predicting the effect of formulation and process variables on performance of the final product throughout its shelf life (3). Preparation of bilayer tablets is gaining importance as it provides a multilayer system for administration of both incompatible and synergistic drugs $(4,5)$. Furthermore, two different APIs or portions of an API with different release characteristics can be formulated as single unit, having different layers. Patient compliance and dosing unit burden can be reduced by combining two or more APIs in a single bilayer tablet (6-8). Therapeutic outcomes can be increased by combining the two APIs in a single unit due to their synergistic effect $(9,10)$. As most bilayer tablets are developed as part of a Life Cycle Management Program, the bilayer technology provides a possibility of prolonging patent life of a drug product $(7,11)$. In recent past, extensive research has been carried out to resolve various problems related to multilayer tablets. The main focus had been on the improvement of structural integrity (prevention of delamination) and mechanical strength of the tablet (higher crushing strength and lower friability). Dissolution testing of bilayer tablets containing different APIs has been neglected by pharmaceutical research. Usually dissolution rate of different APIs, presented in bilayer tablets, is determined according to the protocol for a conventional tablet. Limited data is available about development of dissolution testing methodologies, applicable for different drugs, contained in multilayer tablet.

Platelets play central role in the pathogenesis of atherothrombosis, and antiplatelet therapy has been 
proven to be highly effective in patients with transient ischemic attack or ischemic stroke (12). To achieve better therapeutic outcomes, combination therapy with different classes of antiplatelet agents is carried out. Dual antiplatelet therapy with clopidogrel plus aspirin has been shown to reduce ischemic events in patients with unstable angina and myocardial infarction. Aspirin (2-(acetyloxy) benzoic acid) inhibits cyclooxygenase-dependent platelet aggregation and is commonly used for antiplatelet therapy in low dosage $(75 \mathrm{mg} /$ day); however, a large dosage $(150 \mathrm{mg} /$ day) is used during acute vascular events, like myocardial infarction $(13,14)$.

Clopidogrel (S-methyl2- (2-chlorophenyl) -2- (6,7dihydrothieno $[3,2-c]$ pyridin-5(4H) -yl) acetate) is a new thienopyridine derivative, preventing arterial and venous thrombosis, with a usual dosage of $75 \mathrm{mg} /$ day (15). Clopidogrel blocks activation of platelets by irreversibly inhibiting ADP-dependent activation of the Gpllb-Illa complex, resulting in prevention of platelet aggregation and thrombus formation.

Both aspirin and clopidogrel are antiplatelet agents, acting through different mechanisms and resulting in effective prevention of vascular events in high risk patients (12). For simultaneous administration of aspirin and clopidogrel, bilayer tablets, containing both the drugs in separate layers, have been marketed.

Dissolution methods for single-entity products of clopidogrel and aspirin have been filed with various regulatory agencies. Developing a dissolution method for a combination product of these two drugs was needed to reduce the analysis time and cost. Furthermore, to support the product development efforts, a suitable single dissolution testing method for both the APIs was essential. Clopidogrel is a BCS class-II and has a narrow solubility profile, while aspirin is associated with solubility as well as stability problems. In certain conditions, more than $10 \%$ degradation of aspirin sample has been observed, even before completion of dissolution testing (16). It is a challenging task to develop dissolution testing conditions without any solubility or stability problems.

This paper describes the development and validation of a single dissolution method for bilayer tablets containing clopidogrel and aspirin. The main challenge was to find dissolution media to accommodate the two drugs and produce robust results without any stability and solubility issues. In addition, sample analysis by direct spectrophotometry was unsuitable for the combination product, owing to the lack of specificity, so a highperformance liquid chromatography (HPLC) method was applied for analysis of the dissolution samples. The developed method was applied to evaluate quality of the commercial products marketed during 2015 and 2016 in Peshawar, Pakistan.

\section{MATERIALS AND METHODS}

\section{Materials and instrumentation}

Bilayer tablets containing clopidogrel and aspirin were purchased from a local pharmacy in Peshawar, Pakistan. The clopidogrel bisulfate and aspirin reference standards were provided by Ferozsons Laboratories Ltd. (Nowshera, Pakistan). Other reagents (acetonitrile, $\mathrm{HCl}, \mathrm{NaHPO}_{4}$, and polysorbate 80 ) were purchased from the pharmaceutical market of Peshawar, Pakistan. All reagents were of analytical grade and were used as received.

Purified water was prepared by Milli-Q system (Millipore, Milford, MA, USA). Dissolution studies were performed in a Pharma Test dissolution testing apparatus (Hainburg, Germany), and estimation of the drug content was carried out by HPLC. The HPLC system (Perkin Elmer Series 200, Norwalk, CT, USA) was equipped with an auto sampler, vacuum degasser, Peltier column oven, pump, and UVvisible detector. The chromatographic data was analyzed on PerkinElmer TotalChrom workstation software (version 6.3.1) linked with the LC-system through network chromatography interface ( $\mathrm{NCl}$ ) 900. An ODS C-18 column $(250 \times 4.6 \mathrm{~mm}, 5 \mu \mathrm{m})$ was used as the stationary phase and was protected by a PerkinElmer pre-column guard cartridge C-18 $(30 \times 4.6 \mathrm{~mm}, 10 \mu \mathrm{m})$.

\section{Selection of dissolution media}

Dissolution media was selected on the basis of solubility of both the analytes (clopidogrel and aspirin) and sink conditions during dissolution testing. The flask shake method was used for determination of equilibrium solubility of both the analytes (clopidogrel and aspirin) in various dissolution media (17). An excess of drug was added to the test media, sonicated for $10 \mathrm{~min}$ and subjected to continuous shaking through a mechanical shaker for $24 \mathrm{~h}$ at $37 \pm 2^{\circ} \mathrm{C}$. After completion of the shaking period, the solution was kept undisturbed for $1 \mathrm{~h}$ to achieve the equilibrium, filtered (Whatman filter paper \#42; pore size $=2.5 \mu \mathrm{m}$ ) and analyzed for drug content using HPLC.

Both aspirin and clopidogrel tablets have official monographs in USP-39/NF-34, individually (18). The monograph dissolution media for clopidogrel is $\mathrm{pH} 2 \mathrm{HCl}$ buffer $(1000 \mathrm{~mL})$ held at $37 \pm 2^{\circ} \mathrm{C}$ and agitated at paddle speed of $50 \mathrm{rpm}$. The dissolution rate of aspirin is studied in $0.05 \mathrm{M}$ acetate buffer ( $\mathrm{pH} 4.5 \pm 0.05$ ) using apparatus-I (basket method) at $50 \mathrm{rpm}$. In both the cases, samples are collected after $30 \mathrm{~min}$ and analyzed for drug content. 
In the present study, the dissolution rate from bilayer tablets containing aspirin and clopidogrel was studied in dissolution media recommended for both the drugs separately and media developed on the basis of solubility. Composition of various dissolution media, used in the study, is as follows:

- Purified water

- Purified water containing polysorbate 80 (1\% v/v)

- Purified water ( $\mathrm{pH}$ adjusted to 3 with o-phosphoric acid)

- $\mathrm{HCl}$ buffer ( $\mathrm{pH} 2)$

- $0.05 \mathrm{M}$ acetate buffer (pH 4.5)

- $\mathrm{HCl}$ buffer (pH 3)

Dissolution media providing sink conditions ( $\mathrm{Cs} / \mathrm{Cd} \geq 3$ ) was subjected to further study.

\section{Optimization of experimental conditions}

For selection of optimum testing conditions, various experimental parameters (type of apparatus, agitation rate, and volume of dissolution media) were studied at different levels, as described by USP guidelines, and the effect on dissolution rate was evaluated (18).

The USP recommends two types of the apparatuses for dissolution testing of conventional tablets:

- Apparatus-I: Basket method

- Apparatus-II: Paddle method

For selection of the type of apparatus, dissolution rate was determined using both types of the apparatuses and results were compared in terms of time taken for complete drug release. The apparatus exhibiting faster release was selected for dissolution testing of bilayer tablets.

Considering that rotation speed is a decisive factor influencing the dissolution process, rotation speed of the selected apparatus was evaluated at two levels, 50 and 75 $\mathrm{rpm}$, and the effect on drug release was evaluated.

Volume of dissolution media is the basic parameter for dissolution testing of drugs with poor water solubility. In the present study, volume of dissolution media was optimized by studying dissolution rates using 450 and 900 $\mathrm{mL}$ of dissolution media, and the effect was evaluated.

\section{Dissolution rate studies}

Dissolution rates of clopidogrel and aspirin from bilayer tablets were determined using USP dissolution apparatusII (paddle method) under the optimized experimental conditions. Prior to dissolution testing, dissolution media was sonicated for $5 \mathrm{~min}$ and equilibrated at $37 \pm 2^{\circ} \mathrm{C}$. One tablet was put into the flask of dissolution testing apparatus containing dissolution media held at $37 \pm 2^{\circ} \mathrm{C}$. Aliquots $(5 \mathrm{~mL})$ were withdrawn at specified time intervals (0, $510,15,30,45$, and $60 \mathrm{~min}$ ), filtered, and analyzed for amount of drug release in triplicate $(n=3)$. After each sampling, volume of dissolution media was corrected with the same quantity held at the same temperature.

\section{Determination of drug content of the samples}

During dissolution studies, samples were collected at specified time intervals, filtered, and analyzed for drug release using HPLC. An ODS C-18 column ( $250 \times 4.6$ mm, 5 $\mu \mathrm{m}$ ) was used as a stationary phase and was protected by a PerkinElmer pre-column guard cartridge C-18 (30 × 4.6 $\mathrm{mm}, 10 \mu \mathrm{m})$. The mobile phase consisted of acetonitrile, methanol, and phosphate buffer (50:7:43, v/v/v) pumped at flow rate of $2 \mathrm{~mL} / \mathrm{min}$ at ambient temperature while the detector wavelength was set at $240 \mathrm{~nm}$. Drug content of the sample was calculated by comparison of peak area of the sample and standard solutions containing same concentration of both the analytes (clopidogrel and aspirin). Each sample was analyzed in triplicate and results were presented as mean \pm standard deviation $(n=3)$.

\section{Preparation of standard stock solution}

Stock solutions $(1 \mathrm{mg} / \mathrm{mL}$ ) of clopidogrel and aspirin were prepared using methanol as a solvent. Working solutions were prepared on daily basis by diluting aliquots from stock solution with dissolution media. Each solution was filtered before analysis.

\section{Validation of dissolution method}

According to USP and $\mathrm{ICH}$ guidelines, the selected dissolution method was validated for various parameters like specificity, accuracy, precision and stability as follows $(18,19)$.

\section{Specificity}

Specificity of the dissolution method was evaluated by examining the effect of dissolution media on the peak characteristics (area, height, retention time, and tailing factor) of both the analytes. Dissolution media was evaluated without drug (blank) and with known amount of drug, and results were compared.

\section{Accuracy}

Percent recovery was used for determination of accuracy of the proposed dissolution method. A solution containing $75 \mathrm{mg} / \mathrm{mL}$ of each drug (clopidogrel and aspirin) was prepared in methanol. Aliquots $(0.8,1$ and $1.2 \mathrm{~mL})$ of the solution were added to dissolution media to get the drug concentration in the range of $80-120 \%$ of the nominal dose. Dissolution media was kept at $37 \pm 2^{\circ} \mathrm{C}$ and stirred at $75 \mathrm{rpm}$ for $15 \mathrm{~min}$. Samples $(5 \mathrm{~mL})$ were withdrawn, 
analyzed for drug content, and percent recovery was calculated using following equation:

$$
\text { Percent Recovery }=\frac{A}{B} \times 100 \text {------- Eq-1 }
$$

where

$$
\begin{aligned}
& A=\text { Peak area of the test solution } \\
& B=\text { Peak area of standard solution }
\end{aligned}
$$

For each sample, percent recovery was calculated in triplicate and results were presented in terms of mean, standard deviation, and relative standard deviation (mean \pm SD; \%RSD).

\section{Precision}

Precision of the method was determined in terms of repeatability and intermediate precision. For repeatability, the dissolution test was performed in six vessels of the dissolution testing apparatus simultaneously under the same conditions, and results were compared for variability.

Intermediate precision was evaluated on the basis of intraday and interday studies. The intraday study was performed by repeating the dissolution test three times a day (at 8-h intervals), and the results were compared. For interday study, the dissolution test was repeated on a daily basis (at 24-h intervals) for 3 days under the same conditions, and results were compared for variability Smaller variability, lower SD and \%RSD below 5 indicates acceptable precision of the method and vice versa.

\section{Stability study of solutions}

Stability of solutions was determined at three conditions (low temperature, $2-8^{\circ} \mathrm{C}$; ambient temperature, $24 \pm 3^{\circ} \mathrm{C}$; and elevated temperature, $40 \pm 3^{\circ} \mathrm{C}$ ) for 3 days. Stock solution of each drug (clopidogrel and aspirin) was diluted with dissolution media $(\mathrm{HCl}$ buffer $\mathrm{pH} 3)$ to the specified concentration $(20 \mu \mathrm{g} / \mathrm{mL})$. Each solution was divided into three portions and stored at the specified temperatures for 3 days. Samples were analyzed for drug content on a daily basis, and percent recovery of both analytes was calculated in triplicate. Results were presented as mean \pm SD; \%RSD ( $n=3)$.

\section{Comparison of dissolution profiles}

An independent model approach based on similarity and dissimilarity factors was used for comparison of dissolution profiles (20-22). The similarity factor $\left(f_{2}\right)$ and dissimilarity factor $\left(f_{1}\right)$ were calculated using following equations:

$$
\begin{aligned}
& f_{1}=\frac{\sum[R t-T t]}{\sum R t} \times 100 \text {------- Eq-2 } \\
& f_{2}=50 \times \log \left\{\left[1+(1 / n) \sum\left(R_{\mathrm{t}}-\mathrm{T}_{\mathrm{t}}\right)^{2}\right]^{-0.5} \times 100\right\} \text {------ Eq-3 }
\end{aligned}
$$

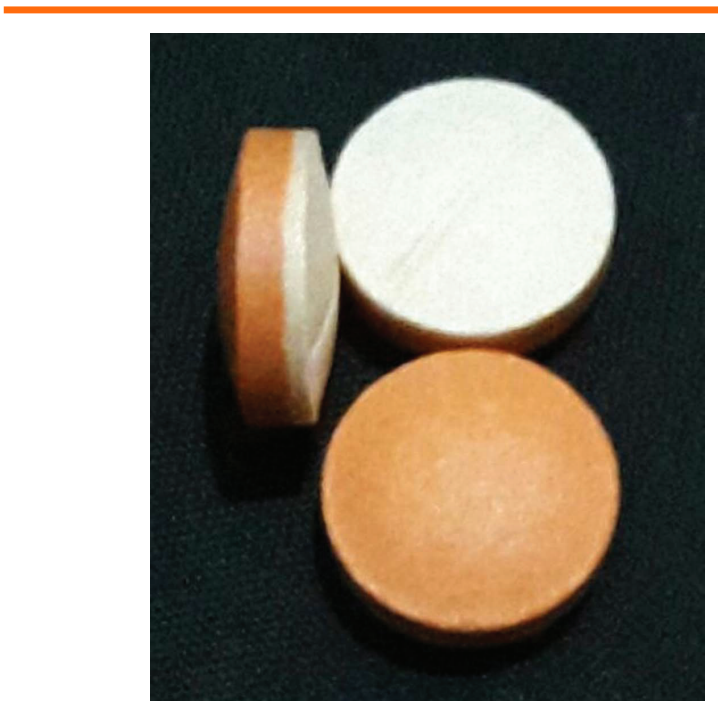

Figure 1. Bilayer tablets containing clopidogrel (orange layer) and aspirin (white layer).

where

$$
\begin{aligned}
& R_{t}=\text { Dissolution rate of standard product at time " } t \text { " } \\
& T_{t}=\text { Dissolution rate of test product at time } t
\end{aligned}
$$

The " $f_{2}$ " value of 50 or greater ensures sameness or equivalence of the two curves.

\section{Application of the method}

The developed method was applied to evaluate the dissolution rate of aspirin and clopidogrel from different batches of the commercial product (bilayer tablets containing clopidogrel and aspirin) produced during 2015 and 2016. Figure 1 shows bilayer tablets containing clopidogrel and aspirin in separate layers that were selected for the study. One tablet was placed in the vessel of the dissolution testing apparatus containing $900 \mathrm{~mL}$ of dissolution media held at $37 \pm 2^{\circ} \mathrm{C}$ and stirred at $75 \mathrm{rpm}$. Aliquots $(5 \mathrm{~mL})$ were withdrawn at specified time intervals $(0,510,15,30,45$, and $60 \mathrm{~min})$, filtered, and analyzed for amount of drug release in triplicate $(n=3)$ using HPLC. After each sampling, the volume of dissolution media was corrected with the same quantity, held at the same temperature. The dissolution rate curve of each batch was developed by plotting cumulative percent drug release versus time, separately.

\section{RESULTS AND DISCUSSION}

Both clopidogrel and aspirin are BCS class-II drugs, having poor water solubility. According to USP guidelines, both drugs are official and dissolution testing has been described in monographs for conventional tablets, individually (18). Aspirin has a narrow, pH-dependent stability profile, is stable at $\mathrm{pH} 2$ to 3 and is least stable at $\mathrm{pH}$ less than 2 
and greater than 8 . In a saturated aqueous solution at $\mathrm{pH}$ $5-7$, aspirin is almost completely hydrolyzed within 1 week at $25^{\circ} \mathrm{C}(16)$. The objective of this study was to develop a single dissolution testing method for bilayer tablets containing clopidogrel and aspirin that can be applied for both the APIs, simultaneously, without any solubility and stability issues.

\section{Selection of dissolution media}

Solubility plays a prime role in dissolution rates, and the correlation is well established (23). In the present study, development of sink conditions on the basis of solubilityto-dose ratio ( $\mathrm{Cs} / \mathrm{Cd}$ ) was used as basic parameter for selection of dissolution media. A sink condition occurs when the amount of drug that can be dissolved in the dissolution medium is three times greater than the amount of drug to be dissolved (24). A low Cs/Cd ratio shows the existence of non-sink conditions with subsequently lower dissolution rates and vice versa. Solubility of clopidogrel and aspirin was determined in different media (purified water, purified water containing $1 \%$ polysorbate 80 , purified water acidified with phosphoric acid, phosphate buffer $\mathrm{pH} \mathrm{4.5,} \mathrm{HCl}$ buffer $\mathrm{pH} \mathrm{2}$, and $\mathrm{HCl}$ buffer $\mathrm{pH} 3$ ), and their dose-to-solubility ratios were calculated as shown in Table 1.

Table 1. Solubility of Clopidogrel and Aspirin in Different Dissolution Media and Correlation with Sink Conditions During Dissolution Testing

\begin{tabular}{|l|c|c|c|c|}
\hline \multirow{2}{*}{ Dissolution Media } & \multicolumn{2}{|c|}{ Clopidogrel } & \multicolumn{2}{c|}{ Aspirin } \\
\cline { 2 - 5 } & $\begin{array}{c}\text { Solubility } \\
(\mathrm{mg} / 900 \mathrm{~mL})\end{array}$ & $\mathrm{C}_{\mathrm{s}} / \mathrm{C}_{\mathrm{d}}$ & $\begin{array}{c}\text { Solubility } \\
(\mathrm{mg} / 900 \mathrm{~mL})\end{array}$ & $\mathrm{C}_{\mathrm{s}} / \mathrm{C}_{\mathrm{d}}$ \\
\hline Purified water & $92.37 \pm 1.51$ & 1.23 & $203.56 \pm 6.33$ & 2.71 \\
\hline $\begin{array}{l}\text { Purified water + } \\
1 \% \text { polysorbate } 80\end{array}$ & $178.94 \pm 3.37$ & 2.38 & $192.73 \pm 3.19$ & 2.57 \\
\hline $\begin{array}{l}\text { Purified water pH } \\
\text { 3+ phosphoric } \\
\text { acid }\end{array}$ & $221.93 \pm 3.42$ & 2.96 & $221.53 \pm 6.03$ & 2.95 \\
\hline $\begin{array}{l}\text { HCl buffer pH 2 } \\
\text { (clopidogrel) }\end{array}$ & $241.65 \pm 2.61$ & 3.22 & $229.06 \pm 2.91$ & 3.05 \\
\hline $\begin{array}{l}\text { Phosphate buffer } \\
\text { pH 4.5 (aspirin) }\end{array}$ & $198.36 \pm 3.72$ & 2.64 & $242.67 \pm 5.09$ & 3.23 \\
\hline HCl buffer $\mathrm{pH} 3$ & $237.91 \pm 2.67$ & 3.17 & $251.33 \pm 5.10$ & 3.35 \\
\hline
\end{tabular}

Results are presented as mean $\pm S D$.

$\mathrm{Cs} / \mathrm{Cd}$, solubility-to-dose ratio; $\mathrm{HCl}$, hydrochloric acid.

Bilayer tablets contain $75 \mathrm{mg}$ of both the drugs (clopidogrel and aspirin), and the same dose was used for determination of sink conditions in different dissolution media. Clopidogrel is practically insoluble in water, and a low solubility-to-dose ratio indicates the non-sink conditions. Similar results were shown by aspirin. Prior to determination of solubility, $\mathrm{pH}$ of purified water was checked and found in the range of $6-7$. Poor $\mathrm{pH}$-dependent solubility of both the drugs was responsible for non-sink conditions in purified water. The use of surfactants in the dissolution media is physiologically relevant and can better simulate the GIT environment (25). Moreover, addition of a small amount of surfactant, below its critical micelle concentration, is often sufficient to solubilize certain drug products. Inclusion of polysorbate $80(1 \% \mathrm{v} / \mathrm{v})$ in the water increased solubility of clopidogrel by $193.72 \%$ with respect to the solubility in purified water but was still short of the sink conditions. Solubility of aspirin in water decreased with inclusion of surfactant, which may due to increase in $\mathrm{pH}$. At higher $\mathrm{pH}$, aspirin shows hydrolysis, resulting in reduced solubility and subsequent dissolution rate (26).

Reducing $\mathrm{pH}$ of purified water to 3 using ortho phosphoric acid significantly increased solubility of both the drugs. In comparison to purified water, solubility of clopidogrel at $\mathrm{pH} 3$ increased by more than $240 \%$, while for aspirin the increase was $108.83 \%$. Similar solubility-to-dose ratios were exhibited by both the drugs and were very close to that for sink conditions ( $\geq 3$ ), as shown in Figure 2 . Use of purified water as dissolution media was not considered further because the sink conditions were not expected (using purified water with and without surfactant) due to smaller solubility-to-dose ratio $(<3)$. Furthermore, use of purified water as dissolution media is not recommended due to limited buffering capacity (2).

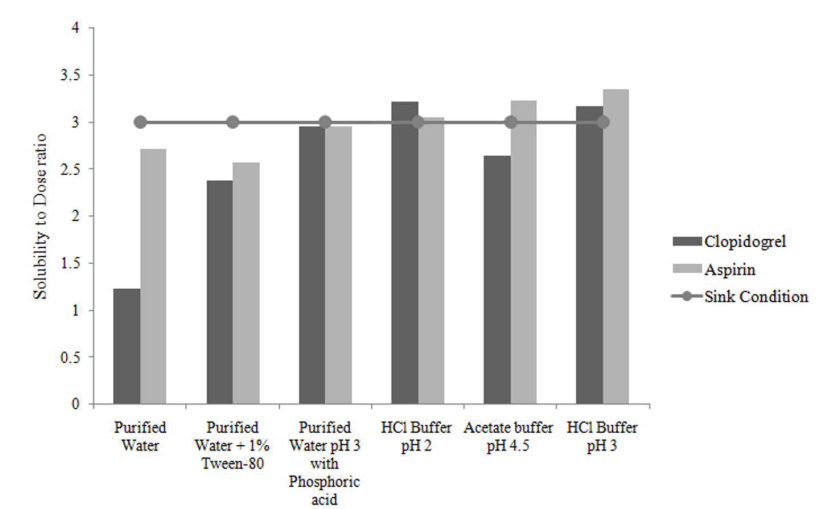

Figure 2. Solubility-to-dose ratio of clopidogrel and aspirin in different dissolution media and correlation with sink conditions

The results depicted in Table 1 show that dissolution media used in the individual USP monographs for conventional tablets of each drug cannot be applied to simultaneous testing of the two drugs. The monograph dissolution media for aspirin was not considered for further screening due to poor dissolution of clopidogrel. However, the dissolution profile of aspirin in the official media for clopidogrel can be improved. 
The highest solubility of both drugs and sink conditions were achieved in $\mathrm{HCl}$ buffer $(\mathrm{pH} 3)$ as shown in Figure 2, and this was selected as dissolution media for further study.

\section{Optimization of experimental conditions}

Along with composition of dissolution media, dissolution testing depends upon various experimental parameters like type of dissolution testing apparatus (USP apparatus I or II), stirring speed and volume of dissolution media. All the experimental conditions were optimized, according to established procedure $(18,19)$.

According to USP guidelines, the dissolution rate of clopidogrel is determined using apparatus-II (paddle method) while apparatus-I (basket method) is recommended for aspirin tablets. Dissolution profiles of both drugs from bilayer tablets showed similar results, with smaller variation in time to achieve the maximum drug release. Values of similarity $\left(f_{1}\right)$ and dissimilarity $\left(f_{2}\right)$ factors also confirmed the similarity of dissolution profiles of both drugs with both types of apparatuses. Apparatus-I resulted in faster dissolution of both drugs and quickly achieved the maximum release, although the difference between apparatuses was very low (less than 10\%). Based on a relatively faster dissolution rate, apparatus-II was selected for dissolution testing of bilayer tablets.

At higher level of volume $(900 \mathrm{~mL})$ of dissolution media, sink conditions were established $(\mathrm{Cs} / \mathrm{Cd}>3$ ) for both drugs and the effect of agitation rate was evaluated on the basis of time required for maximum drug release. Both analytes exhibited different dissolution profiles by varying speed of the paddle (50 and $75 \mathrm{rpm})$. At higher speed $(75 \mathrm{rpm})$, maximum release of both drugs was observed in a shorter time (45 min) using $900 \mathrm{~mL}$ of dissolution media, while at slower paddle speed ( $50 \mathrm{rpm}$ ), $60 \mathrm{~min}$ was needed for complete release. At a lower volume $(450 \mathrm{~mL})$ and paddle speed $(50 \mathrm{rpm})$, maximum release of both the drugs was below $60 \%$. By increasing the agitation rate, $8.81 \%$ and $6.65 \%$ increase in maximal release was observed for clopidogrel and aspirin, respectively. Decreases in dissolution rates of both drugs were due to the lack of sink conditions ( $\mathrm{Cs} / \mathrm{Cd}>3)$. By decreasing volume of dissolution media, the sink conditions are lost and dissolution of both
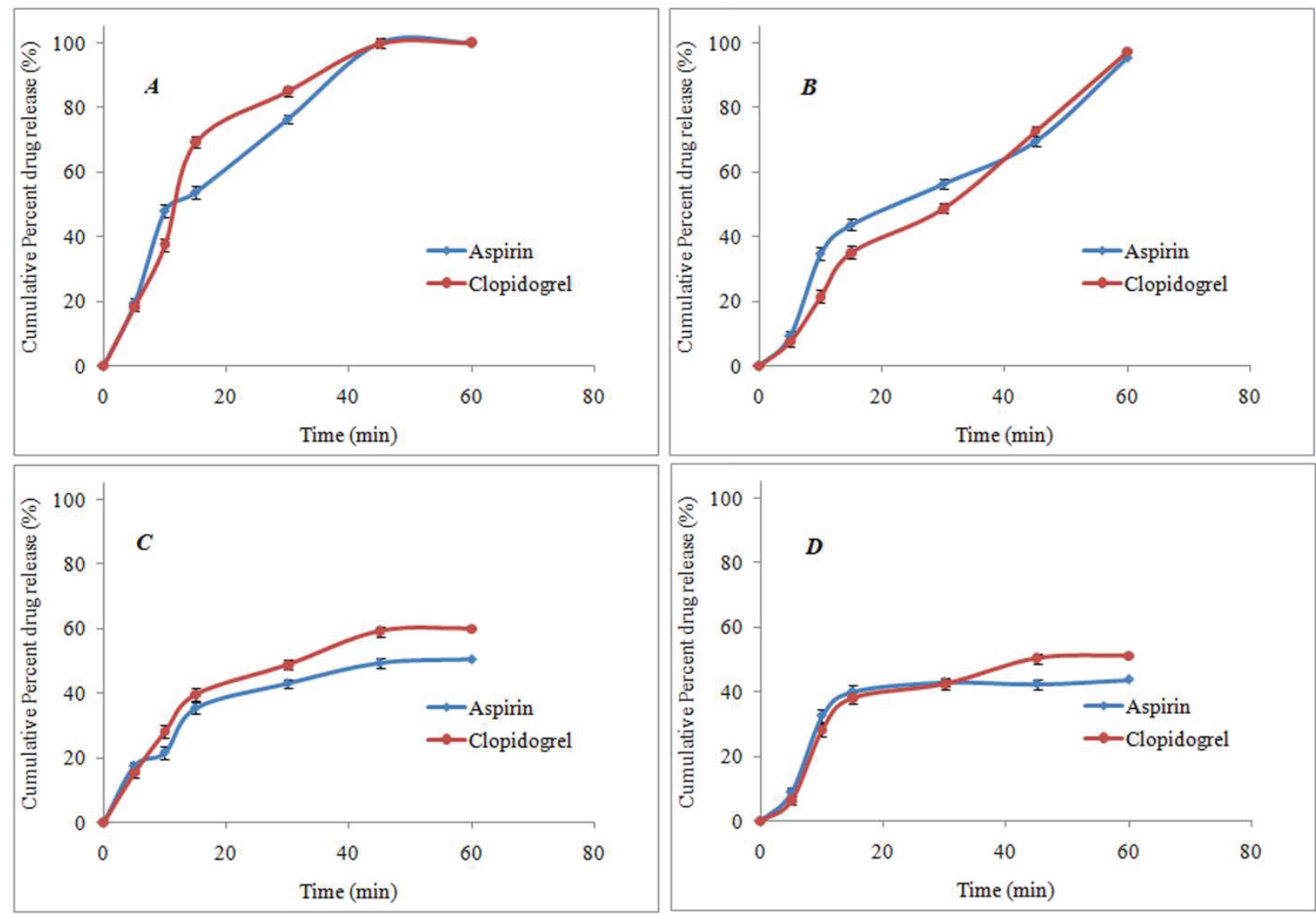

Figure 3. Effect of rotation speed of the apparatus-II (paddle) on dissolution rate at different volumes of dissolution media (HCl buffer pH 3). (A) $75 \mathrm{rpm}, 900 \mathrm{~mL}$; (B) $50 \mathrm{rpm}, 900 \mathrm{~mL}$; (C) $75 \mathrm{rpm}, 450 \mathrm{~mL}$; (D) $50 \mathrm{rpm}, 450 \mathrm{~mL}$. 
drugs decreased, significantly. The effect of paddle speed on dissolution at different levels of volume is presented in Figure 3.

Hydrochloric acid buffer $(\mathrm{pH} 3)$ resulted in the best dissolution profile of both drugs at a higher volume $(900$ $\mathrm{mL}$ ) and paddle speed (75 rpm). Both drugs were released maximally, i.e. up to $100 \%$, within 45 min (Figure 4). Hence, USP apparatus-II at $75 \mathrm{rpm}$ with $900 \mathrm{~mL}$ of $\mathrm{HCl}$ buffer $\mathrm{pH} 3$ were chosen as the conditions for the dissolution method. The release profile of both drugs obtained in the developed dissolution test was considered satisfactory, as shown in Figure 4.

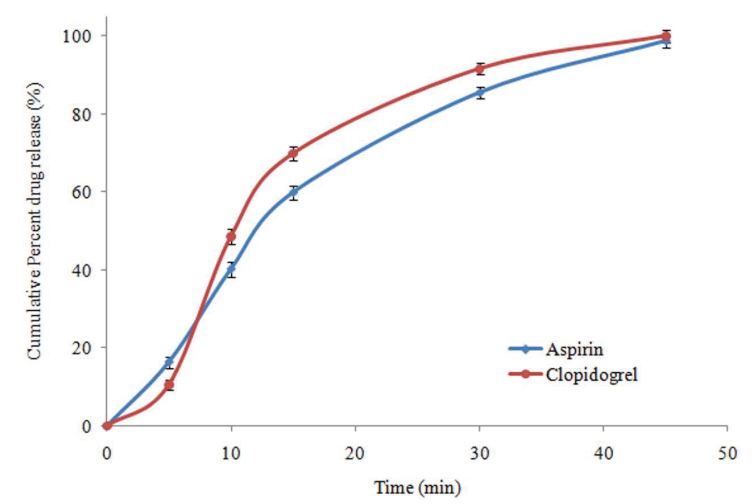

Figure 4. Dissolution profile of clopidogrel and aspirin from bilayer tablets.

Validation of the developed dissolution testing method Based on the obtained results, $900 \mathrm{~mL}$ of $\mathrm{HCl}$ buffer $\mathrm{pH} 3$ with a paddle speed of $75 \mathrm{rpm}$ was selected as dissolution test conditions for bilayer tablets containing clopidogrel and aspirin. The developed dissolution testing method was validated in accordance with USP and ICH guidelines.

\section{Specificity}

Specificity of the method was estimated by chromatographic response of the blank dissolution media and dissolution media containing different concentrations of clopidogreland aspirin. The chromatogram of dissolution media was free of any interfering peak while different concentrations of both analytes exhibited peaks with concentration-dependent area and constant retention time. Peak purity was further confirmed by examining through peak purity tool, provided in the HPLC software. The obtained value for peak purity of both drugs was $\approx 1$, indicating acceptable purity of the peak. Representative chromatograms of both drugs in dissolution media (real samples) are presented in Figure 5. Peaks of both drugs are well resolved, having better peak area and peak height.

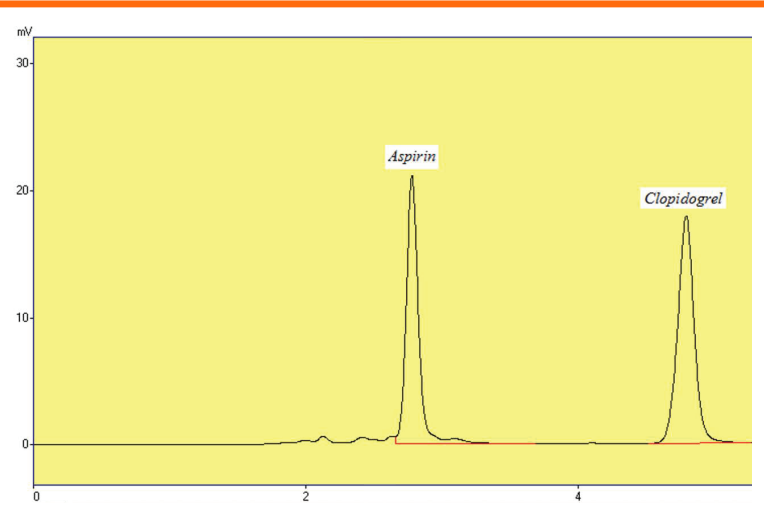

Figure 5. HPLC chromatogram of clopidogrel and aspirin, representing real dissolution sample. Dissolution media consisted of $\mathrm{HCl}$ buffer ( $p \mathrm{H} 3)$.

\section{Accuracy}

Accuracy of the method was evaluated by percent recovery. A recommendation for best accuracy of the method is percent recovery within the range of 95.0$105.0 \%$. The observed mean recovery for clopidogrel was in the range of 98.72 to $100.03 \%$, while that of aspirin was almost $100 \%$ (Table 2), indicating accuracy of the dissolution method.

\section{Precision}

Results for the intraday and interday precision studies are summarized in Table 2 . All results are in close agreement with each other and the \%RSD value is less than $1 \%$ for both drugs, indicating good precision of the method.

\section{Stability of solutions}

Stability of solutions of both analytes prepared in dissolution media ( $\mathrm{HCl}$ buffer $\mathrm{pH}$ 3) was evaluated for 3 days. Clopidogrel content of the samples was within the range of $99.32-99.83 \%$ of the initial value over the test period ( 3 days), and no degradation products were observed in any of the chromatograms, indicating good stability in dissolution media. The stock solution of aspirin (prepared in methanol) remained stable for the study period, while the samples prepared in dissolution media degraded significantly, especially at elevated temperature $\left(40 \pm 3^{\circ} \mathrm{C}\right)$, as shown in Table 3. Degradation of aspirin samples has been reported, and our results indicate that dissolution samples containing aspirin should be analyzed within $24 \mathrm{~h}$ of sampling (27).

\section{Application of the method}

Bilayer tablets containing clopidogrel and aspirin, marketed in Peshawar, Pakistan, during 2015 and 2016 were evaluated for quality based on the drug release profile using the developed dissolution testing method. Only the batches having passed at least 6 months of shelf life were included in the study, and all the batches were analyzed before their expiry date. A total of six batches 
Table 2. Validation Parameters for the Developed Dissolution Method.

\begin{tabular}{|c|c|c|}
\hline Parameter & Clopidogrel & Aspirin \\
\hline \multicolumn{3}{|l|}{ Accuracy } \\
\hline $60 \mathrm{mg}(80 \%)(\mathrm{n}=3)$ & $100.03 \pm 0.61 ; 0.61$ & $99.51 \pm 0.86 ; 0.86$ \\
\hline $75 \mathrm{mg}(100 \%)(\mathrm{n}=3)$ & $99.72 \pm 0.43 ; 0.43$ & $99.28 \pm 0.73 ; 0.74$ \\
\hline $90 \mathrm{mg}(120 \%)(\mathrm{n}=3)$ & $99.81 \pm 0.29 ; 0.29$ & $100.01 \pm 0.69 ; 0.69$ \\
\hline \multicolumn{3}{|l|}{ Precision } \\
\hline \multicolumn{3}{|l|}{ Repeatability } \\
\hline Vessel $1(V 1)(n=3)$ & $100.16 \pm 0.59 ; 0.59$ & $99.68 \pm 0.27 ; 0.27$ \\
\hline Vessel $2(V 2)(n=3)$ & $99.26 \pm 0.78 ; 0.79$ & $100.03 \pm 0.73 ; 0.73$ \\
\hline Vessel $3(V 3)(n=3)$ & $99.89 \pm 0.62 ; 0.62$ & $99.92 \pm 0.51 ; 0.51$ \\
\hline Vessel $4(V 4)(n=3)$ & $99.33 \pm 0.39 ; 0.39$ & $99.67 \pm 0.58 ; 0.58$ \\
\hline Vessel $5(V 5)(n=3)$ & $100.21 \pm 0.58 ; 0.58$ & $100.01 \pm 61 ; 0.61$ \\
\hline Vessel $6(V 6)(n=3)$ & $100.06 \pm 0.37 ; 0.37$ & $99.48 \pm 0.56 ; 0.56$ \\
\hline \multicolumn{3}{|c|}{ Intermediate precision } \\
\hline \multicolumn{3}{|c|}{ Intraday reproducibility } \\
\hline $8 h(n=3)$ & $99.93 \pm 0.42 ; 0.42$ & $100.09 \pm 0.36 ; 0.36$ \\
\hline $16 \mathrm{~h}(\mathrm{n}=3)$ & $99.86 \pm 0.23 ; 0.23$ & $99.73 \pm 0.67 ; 0.67$ \\
\hline $24 \mathrm{~h}(\mathrm{n}=3)$ & $100.19 \pm 0.71 ; 0.71$ & $99.82 \pm 0.48 ; 0.48$ \\
\hline \multicolumn{3}{|c|}{ Interday reproducibility } \\
\hline Day $1(n=3)$ & $99.93 \pm 0.42 ; 0.42$ & $100.09 \pm 0.36 ; 0.36$ \\
\hline Day $2(n=3)$ & $99.69 \pm 0.38 ; 0.38$ & $99.51 \pm 0.42 ; 0.42$ \\
\hline Day $3(n=3)$ & $100.03 \pm 0.57 ; 0.57$ & $99.19 \pm 0.65 ; 0.66$ \\
\hline
\end{tabular}

Results are presented as mean $\pm S D ; \% R S D$.

Dissolution testing conditions were: dissolution media, $\mathrm{HCl}$ buffer ( $\mathrm{pH}$ 3); temperature, $37 \pm 2^{\circ} \mathrm{C}$; paddle speed, $75 \mathrm{rpm}$; volume of dissolution media, $900 \mathrm{~mL}$.

Table 3. Stability (Percent Recovery) of Clopidogrel and Aspirin from Solutions Prepared in Methanol and Dissolution Media After Storage at Different Conditions for 3 Days

\begin{tabular}{|c|c|c|c|c|}
\hline \multirow[b]{2}{*}{ Analyte } & \multirow[b]{2}{*}{ Composition of Solvent } & \multicolumn{3}{|c|}{ Percent Recovery (\%) } \\
\hline & & $\begin{array}{c}\text { Ambient Temperature } \\
\left(24 \pm 3^{\circ} \mathrm{C}\right)\end{array}$ & $\begin{array}{l}\text { Refrigerator Temperature } \\
\qquad\left(2-8^{\circ} \mathrm{C}\right)\end{array}$ & $\begin{array}{l}\text { Elevated Temperature } \\
\left(40 \pm 3^{\circ} \mathrm{C}\right)\end{array}$ \\
\hline \multirow{3}{*}{ Clopidogrel } & Stock solution (methanol) & $99.32 \pm 0.69$ & $99.81 \pm 0.79$ & $99.66 \pm 0.22$ \\
\hline & Developed dissolution media & $99.58 \pm 0.74$ & $99.37 \pm 0.28$ & $99.41 \pm 0.39$ \\
\hline & Official dissolution media & $99.67 \pm 0.35$ & $99.54 \pm 0.61$ & $99.83 \pm 0.52$ \\
\hline \multirow{3}{*}{ Aspirin } & Stock solution (methanol) & $99.68 \pm 0.23$ & $100.13 \pm 0.52$ & $99.62 \pm 0.71$ \\
\hline & Developed dissolution media & $89.26 \pm 0.39$ & $90.28 \pm 0.67$ & $85.73 \pm 0.69$ \\
\hline & Official dissolution media & $90.32 \pm 0.51$ & $92.46 \pm 0.29$ & $91.20 \pm 0.40$ \\
\hline
\end{tabular}

Results are presented as mean $\pm S D(n=3)$.

Developed dissolution media, $\mathrm{HCl}$ buffer ( $\mathrm{pH}$ 3); clopidogrel official dissolution media, $\mathrm{HCl}$ buffer ( $\mathrm{pH}$ 2); aspirin official dissolution media, $0.05 \mathrm{M}$ acetate buffer ( $p H$ 4.5). 

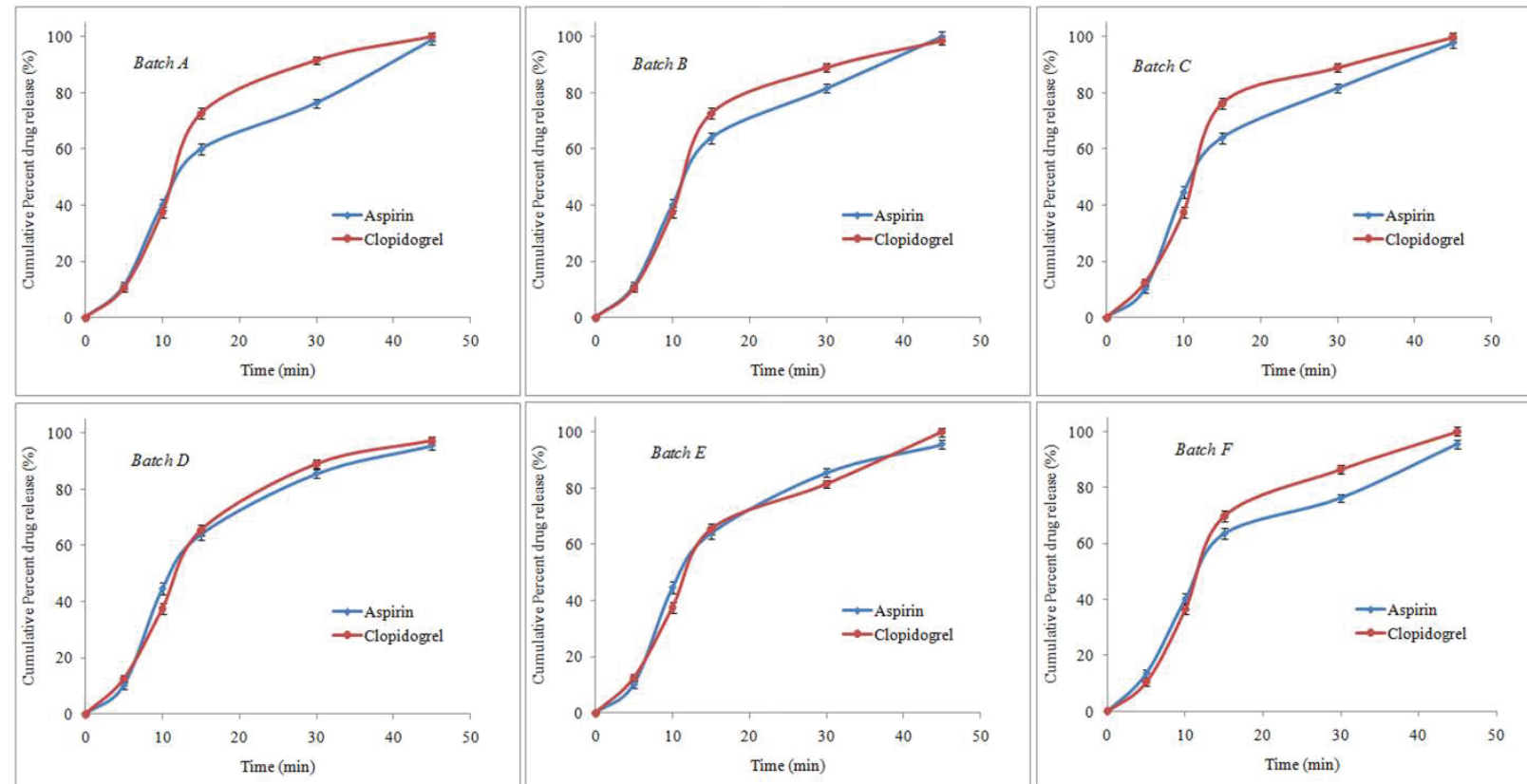

Figure 6. Dissolution profile of six different batches (Batch A-F). of bilayer tablets containing clopidogrel and aspirin, marketed during 2015 and 2016.

were selected, of which four batches were manufactured during 2015 and two during 2016. Drug release from all batches was similar and within the official limits for both the drugs (18). Dissolution profiles of all the tested batches are presented in Figure 6.

\section{CONCLUSION}

In the present study, a robust accurate dissolution testing method was developed for bilayer tablets containing clopidogrel and aspirin and validated according to USP and ICH guidelines. Solubility of both APIs was determined in different dissolution media, and sink conditions were evaluated. Dissolution media was selected on the basis of sink conditions for both drugs, and various test conditions were optimized. The use of $900 \mathrm{~mL}$ of $\mathrm{HCl}$ buffer $(\mathrm{pH} 3)$ as dissolution media held at $37 \pm 2^{\circ} \mathrm{C}$ and stirred at $75 \mathrm{rpm}$ produced satisfactory results. Dissolution testing of bilayer tablets containing clopidogrel and aspirin was evaluated in the selected dissolution media under the optimized test conditions, resulting in complete drug release within 45 min. Validation parameters revealed accuracy, precision, and robustness of the method without any interference with the analysis. The developed method will be helpful in dissolution testing of bilayer tablets containing clopidogrel and aspirin at the level of product development and during routine quality control analysis and post-marketing surveillance studies.

\section{ACKNOWLEDGEMENT}

We are thankful to the management of Ferozsons Laboratories Ltd., Nowshera, Pakistan, for provision of clopidogrel and aspirin reference standards.

\section{CONFLICT OF INTEREST}

The author claims no conflict of interest.

\section{REFERENCES}

1. de Souza Anselmo, C.; de Carvalho Mendes, T; da Silva Honorio, T.; do Carmo, F.A.; Cabral, L.M; de Sousa, V.P. Development and validation of a dissolution test for lutein tablets and evaluation of intestinal permeability. Food Chemistry 2016, 210, 63-69. DOI: http://dx.doi.org/10.1016/j.foodchem.2016.04.081.

2. Singla, N.; Gupta, G. D.; Kohli, K.; Singla, A. K. A discriminatory and biorelevant dissolution test method for simvastatin drug products. Dissolution Technol. 2009, 11-13. DOI: dx.doi. org/10.14227/DT160409P11.

3. Bonfilio, R.; Pires, S.A.; Ferreira, L.M.; de Almeida, A.E.; Doriguetto, A.C.; de Araújo, M.B.; Salgado, H.R. A discriminating dissolution method for glimepiride polymorphs. J. Pharm. Sci. 2012, 101, 794-804. DOI: 10.1002/jps.22799.

4. Abebe, A.; Askseli, I.; Sprockel, O.; Kottala, N.; Cuitiño, A.M. Review of bilayer tablet technology. Int. J. Pharm. 2014, 461, 549-558. DOI: http://dx.doi.org/10.1016/j.jpharm.2013.12.028.

5. Ilgaz, A.; Admassu, A.; Omar, S.; Alberto, M.C. Mechanistic characterization of bilayer tablet formulations. Powder Techol. 2013, 236, 30-36. DOI: https://doi.org/10.1016/j. 
powtec.2012.05.048.

6. Junier, L.R. Determination of salicylate in blood serum using an amperometric biosensor based on salicylate hydroxylase immobilized in a polypyrrole-glutaraldehyde matrix. Talanta 2000, 51 (3), 547-557. DOI: https://doi.org/10.1016/s00399140(99)00311-2.

7. Belda, P.M.; Mielck, J.B. Considerations about the theoretically expected crushing strength of tablets from binary powder mixtures: double layer tablets versus arithmetic additivity rule. Eur. J. Pharm. Biopharm. 2006, 64, 343-350. DOI: 10.1016/j. ejpb.2006.06.007.

8. Podczeck, F.; Drake, K. R.; Newton, J. M.; Haririan, I. The strength of bilayered tablets. Eur. J. Pharm. Sci. 2006, 29, 361-366. DOI: 10.1016/j.ejps.2006.07.005.

9. Conte, U.; Maggi, L. Modulation of the dissolution profiles from Geomatrix ${ }^{\circledR}$ multi-layer matrix tablets containing drugs of different solubility. Biomoterials 1996, 17, 889-896. DOI: https:// doi.org/10.1016/0142-9612(96)83284-4.

10. Asare-Addo, K.; Supuk, E.; Mahdi, M.H.; Adebisi, A.O.; Nep, E. Conway, B.R.; Kaialy, W.; Al-Hamidi, H.; Nokhodchi, A. Drug release from $E$ chemistry hypromellose tablets using the Bio-Dis USP type III apparatus: An evaluation of the effect of systematic agitation and ionic strength. Colloid. Surf. B: Biointerfaces 2016, (143), 481489. DOI: http://dx.doi.org/doi:10.1016/j.colsurfb.2016.03.066.

11. Diener, H-C.; Bogousslavsky, J.; Brass, L.M.; Cimminiello, C.; Csiba, L.; Kaste, M.; Leys, D.; Matias-Guiu, J.; Rupprecht, H-J.. Aspirin and clopidogrel compared with clopidogrel alone after recent ischaemic stroke or transient ischaemic attack in high-risk patients (MATCH): randomized, double-blind, placebo-controlled trial. Lancet. 2004, 364, 331-37. DOI: https://doi.org/10.1016/ s0140-6736(04)16721-4.

12. The Clopidogrel in Unstable Angina to Prevent Recurrent Events Trial Investigators Effects of clopidogrel in addition to aspirin in patients with acute coronary syndromes, without ST-segment elevation. N. Engl. J. Med. 2001, 345 (7), 494-502. DOI: https:// doi.org/10.1056/nejmoa010746.

13. Serebruany, V. L.; Malinin, A. I.; Sane, D. C.; Jilma, B.; Takserman, A.; Atar, D.; Henneckens, C. H. Magnitude and time course of platelet inhibition with Aggrenox ${ }^{\circledR}$ and aspirin in patients after ischemic stroke: the AGgrenox versus Aspirin Therapy Evaluation (AGATE) trial. Eur. J. Pharmacol. 2004, 3, 315-324. DOI: https:// doi.org/10.1016/j.ejphar.2004.07.114.

14. CAPRIE Steering Committee. A randomised, blinded, trial of clopidogrel versus aspirin in patients at risk of ischaemic events (CAPRIE). Lancet. 1996, 348, 1329-1339. DOI: https://doi. org/10.1016/s0140-6736(96)09457-3.

15. Effat, S.; Hassan, J.; Abbas, K.; Maral, S.; Afshin, D. Validated HPLC method for determination of carboxylic acid metabolite of clopidogrel in human plasma and its application to a pharmacokinetic study. Biomed. Chromatogr. 2006, 20,
1309-1314. DOI; doi.org/10.1002/bmc.697.

16. al-Gohary, O.M.; al-Kassas, R.S. Stability studies of aspirinmagaldrate double layer tablets. Pharm. Acta Helvetiae. 2000, 74, 351-360. DOI: 10.1016/S0031-6865(99)00045-X.

17. Ashokraj, Y.; Daroi, A.; Gupta, R.; Khanolkar, A.; Kulkarni, A.; Laud, S.; Pokale, M.; Shedge, S.; Date, P. Discriminatory dissolution method development and validation of etoricoxib tablets. Dissolution Technol. 2016, 30-34. DOI: dx.doi.org/10.14227/ DT230216P30.

18. The United States Pharmacopeia and National Formulary USP38-NF-33. United States Pharmacopeial Convention, Inc.: Rockville, MD, 2015.

19. Singh, B.; Ahuja, N. Development of controlled-release buccoadhesive hydrophilic matrices of diltiazem hydrochloride: optimization of bioadhesion, dissolution and diffusion parameters. Drug. Dev. Ind. Pharm. 2002, 28, 431-442. DOI: https://doi.org/10.1081/ddc-120003004.

20. Note for Guidance on Validation of Analytical Procedures: Text and Methodology; CPMP/ICH/381/95, European Medicines Agency: London, 1995.

21. Costa, P.; Sousa Lobo, J.M. Modeling and comparison of dissolution profiles, Eur. J. Pharm. Sci. 2001, 13, 123-133. DOI: 10.1016/S0928-0987(01)00095-1.

22. Pseidy, L. M.; Roberto, R.; María, D. V. Matrix tablets: The effect of hydroxypropyl methylcellulose/anhydrous dibasic calcium phosphate ratio on the release rate of a water-soluble drug through the gastrointestinal tract I. In vitro tests. AAPS PharmSciTech. 2012, 13 (4), 1073-1083. DOI: 10.1208/s12249012-9829-9.

23. Javadzadeh, Y.; Jafari-Navimipour, B.; Nokhodchi, A. Liquisolid technique for dissolution rate enhancement of a high dose waterinsoluble drug (carbamazepine). Int. J. Pharm. 2007, 341, 26-34. DOI: 10.1016/j.ijpharm.2007.03.034.

24. Cristofoletti, R.; Dressman, J.B. Dissolution methods to increasing discriminatory power of in vitro dissolution testing for ibuprofen free acid and its salts. J. Pharm. Sci. 2017, 92-99. DOI: http:// dx.doi.org/10.1016/j.xphs.2016.06.001.

25. Brown, C.K.; Chokshi, H.P.; Nickerson, B.; Reed, R.A.; Rohrs, B.R.; Shah, P.A. Acceptable analytical practices for dissolution testing of poorly soluble compounds. Pharm. Technol. 2004, 56-65. DOI: https://doi.org/10.14227/dt120405p6.

26. Quereshi, S.A. Developing discriminatory drug dissolution tests and profiles: Some thoughts for consideration on the concept and its interpretation. Dissolution Technol. 2006, 18-23. DOI: dx.doi.org/10.14227/DT130406P18.

27. Bakar, S.K.; Niazi, S. Stability of aspirin in different media. J. Pharm. Sci. 1983, 72 (9), 1024-1026. DOI: https://doi. org/10.1002/jps.2600720914. 